\title{
Book Review Urban and Environmental Economics: An Introduction
}

Graham Squires, Routledge, London, 2013, 214 pp. ISBN 978-0-415-61991-2 (pbk), ISBN 9780-415-61990-5 (hbk), ISBN 978-0-203-82599-0 (ebk), GBP29.99 (pbk) GBP 105.00 (hbk), USD49.95 (pbk), USD170.00 (hbk).

Let me start by saying that I enjoyed Urban and Environmental Economics: An Introduction, although because it is packed by information on a wide range of topics it is not necessarily easy to read. It is also a very ambitious book in areas where most material seems written for underachievers. According to the publisher's web site:

Those new to, or preparing to join this industry must have an understanding of how their environmental responsibilities relate to their professional responsibilities in economic terms.

Designed as an introductory textbook, Urban and Environmental Economics: An Introduction provides the background information from these disciplines to understand crucial tools and economic techniques. A broad range of theories of the natural and built environments and economics are explained, helping the reader develop a real understanding of the topics that influence this subject, such as:

-the history of economic thought on the built environment

-the economics of shared space in the built environment

-cost-benefit analysis and discounting

-macro-economic tools, measures, and policy

-sustainable development

-resource valuation.

For a book of 214 pages these are very ambitious aims, with so many subjects that would seem to justify books on their own. To illustrate the breath of the content the chapter headings include Market Forces: Supply and Demand, The Built and Natural Environment According to Economists, Cost Benefit Analysis, Limits to Growth: Balancing Space and Resources, Macroeconomic Government Objectives and Policy, Environmental Resources and Use in Urban Space to mention just a selection.

The inevitable outcomes of this kind of perspective are firstly that expositions are very compact and secondly, that there are many issues that could legitimately claim more space than they are given. Economic concepts like opportunity costs and supply and demand are discussed, but more for general knowledge than at a level where they may be used for analysis.

On the other hand, providing this broad background serves to demonstrate the interconnection between subjects and the applicability of economic theory, and analytical techniques over a wide range of topics of real importance to current political choices and future living conditions. The book has the potential to make the reader interested in additional studies and points to the necessity of an economic framework for a meaningful analysis. It's a good preparation for further studies.

Because the treatment of the various issues in the book is so compact and the book covering so many areas, using it as a text would give a lot of freedom to select topics to deal with in a 
course. It would also require lectures or tutorials to expand on the selected topics, and to show how the theories and concepts can be used to deepen the analyse of these and other complex problems.

In summary, the broad range of topics is both the strength and weakness of the book. For most purposes the strength outweighs any weakness for what is a very good introduction to the interactions between economics, the environment and the use of urban space. It is informative and the reader is likely to get interested in the problems, how they may be analysed and what may be solutions. As a textbook it provides opportunities for the lecturer to be selective and emphasise what he or she considers to be the main issues.

Dr Göran Runeson

University of Western Sydney, Australia 